\title{
SURFACE STRESS EVOLUTION AND CRACKS PREVENTION OF INGOTS DURING THE UPSETTING PROCESS
}

\author{
Guofa $\mathrm{Mi}^{1}$ - Juanjuan Wei ${ }^{1}-\mathrm{Bin}_{\mathrm{Xu}^{2,3^{*}}-\text { Mingyue Sun }}{ }^{2,3}-$ Junqiang Zhang ${ }^{1,2}$ \\ ${ }^{1}$ School of Material Science and Engineering; Henan Polytechnic University; 2001 Shiji Road, Jiaozuo, Henan, 454003, \\ P. R. China \\ ${ }^{2}$ Shenyang National Laboratory for Materials Science; Institute of Metal Research, Chinese Academy of Sciences; 72 \\ Wenhua Road, Shenyang, Liaoning, 110016, P. R. China \\ ${ }^{3}$ Key Laboratory of Nuclear Materials and Safety Assessment; Institute of Metal Research; 72 Wenhua Road, \\ Shenyang, Liaoning, 110016, P. R. China
}

\begin{tabular}{l} 
ARTICLE INFO \\
\hline Article history: \\
Received: 6.4.2018. \\
Received in revised form: 10.9.2018. \\
Accepted: 21.9.2018. \\
\hline Keywords: \\
Surface stress \\
Axial stress \\
Surface cracks \\
Bulging \\
Upsetting
\end{tabular}

DOI: http://doi.org/10.30765/er.39.3.10

\section{Introduction}

Large forgings are the key components of large equipment [1]. Large ingots are the main raw material for producing large forgings [2]. During the hot forging process of large ingots, the uneven deformation, high temperature, and large forming force may lead to cracks or even fracture [3-5]. For example, turbine blade, pipe, pressure vessel or

\begin{abstract}
:
In this research, surface axial stress and propagation of surface transverse cracks on large ingots during hot forging process was studied using finite element modeling. The simulation results show that surface axial stress changes from compressive to tensile during the upsetting process. Large ingots which need to be upset and stretched several times are easy to form cracks at anvil overlapping part during stretching process. These surface transverse cracks are crack source and may rapidly propagate under surface axial tensile stress during the upsetting process. The effect of material, temperature, height-diameter ratio of billet, deformation speed, and friction coefficient between anvil and billet on the changing of surface axial stress was investigated. The results show that critical transformation point of surface axial stress from compressive to tensile has an obvious relationship with drum shape of the billet. In order to eliminate the surface axial tensile stress and prevent propagation of surface transverse cracks, a slim waist forging process was proposed based on the surface stress analysis. A quantitative designing method of slim waist billet was established for guiding industrial production.
\end{abstract}

power plant generator rotor often cracks during its hot forging process. More and more researchers pay attention to this problem because cracking may lead to prolonging production period, increasing production cost, or even failure of the product [6-8]. Forging process can crush the as-cast dendritic structure, refine the internal grain structure, and improve material strength and toughness of the forgings. When the material plasticity is low or the

\footnotetext{
* Corresponding author. +86-24-8397-8839; fax: +86-24 83970097

E-mail address: bxu@imr.ac.cn.
} 
deformation is large, cracks often occur on the side surface of the billet, which would affect the subsequent forging process $[9,10]$. Cracks may form under the influence of external conditions including force, deformation temperature, reduction ratio and surface quality of the ingot. During forging process, stress is an important factor causing cracks. Besides the force from dies, there are other types of stress like circumferential stress caused by uneven deformation, thermal stress caused by uneven temperature and structural stress caused by unsynchronized structural transformation during forging process of the billet [11-13].

A crack is a common defect in the deformation process of large forgings. The majority of the current studies suggest that surface cracks are mainly caused by surface circumferential tensile stress during the upsetting process. Large tensile stress may cause the material overload in circumferential direction and micro pores and holes may appear and expand, which finally leads to macroscopic crack and fracture [1416]. However, there are many types of cracks, and circumferential stress can only cause longitudinal crack on billet surface. So regarding circumferential tensile stress as the only factor causing surface crack is not reasonable. In our research it is found that during the upsetting process, as the reduction ratio increases, there will be not only circumferential tensile stress but also axial tensile stress on the surface of the billet. The two direction tensile stress states have an important impact on surface crack propagation. However, in many studies, the effect of axial tensile stress on surface cracks was neglected $[17,18]$.

Takefumi Arikawa et al. analyzed surface defects formed at anvil overlapping part during stretching process [11]. The formation process of surface defects at anvil overlapping part is shown in Figure 1. The stretching process and a picture of surface defects at anvil overlapping part is shown in Figure 2. The surface defects will form at anvil overlapping part during stretching process, and these defects may propagate and lead to forging crack or fracture on the surface of the forging billet during the following forging process. (a) Anvil overlapping part

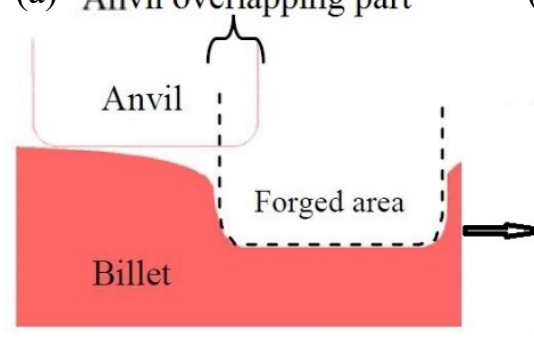

(b)

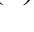

(c)

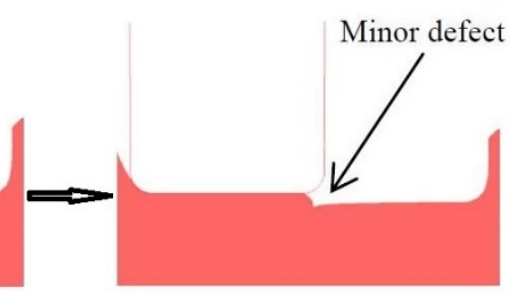

Figure 1. The formation process of surface defects at anvil overlapping part (a) stroke $=0 \mathrm{~mm}$; (b) stroke $=15$ $\mathrm{mm} ;$ (c) stroke $=30 \mathrm{~mm}[11]$.

(a)

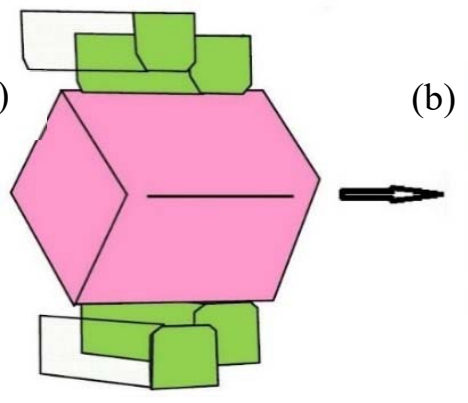

(b)

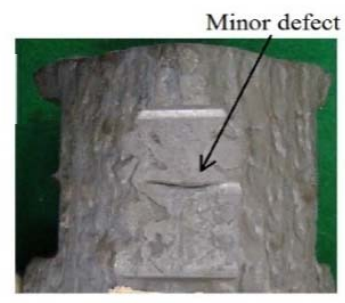

Figure 2. Surface defects formed at anvil overlapping part during stretching process (a) Stretching process (b) Forged billet with minor defect [11].

In order to improve the quality of heavy forgings, repeated upsetting and stretching should be performed. During the stretching process, surface transverse cracks may form at anvil overlapping part, and these minor cracks lie along the circumferential direction, as Fig. 1 shows. These minor cracks 
become crack source and will rapidly propagate under the surface axial tensile stress during the following upsetting. These minor defects can be eliminated by hot scarfing, but some small ones may still be left over. For 316 stainless steel, super alloy and other steels with cracking tendency which cannot be hot scarfed, cracks are easily formed and propagated during repeated upsetting and stretching, while treating these cracks are difficult and time consuming. So surface stress state and cracking tendency has to be studied, and new effective forging method for controlling surface cracking has to be proposed.

Surface axial stress transformation from compressive to tensile during upsetting process is studied in this paperby finite element modeling, and the effect of material, temperature, height-diameter ratio of billet, deformation speed, and friction coefficient between anvil and billet on the transformation point of surface axial stress was investigated. The rule of surface axial stress transformation from compressive to tensile was studied, and a new slim waist forging process was proposed based on the rule, which can provide guidance for industrial production.

\section{Numerical analysis of surface stress during upsetting process}

Deform-3D is a finite element software and can provide extremely valuable data analysis including temperature field, stress field, and strain field [19]. The upsetting process was calculated and analyzed using Deform-3D. Considering that the surface stress during the deformation of the cylindrical billet is easier to analyze than the surface stress of the square billet, finite element model of a $\Phi 1 \mathrm{~m} \times 1.4 \mathrm{~m}$ billet was established as Fig. 3 shows.

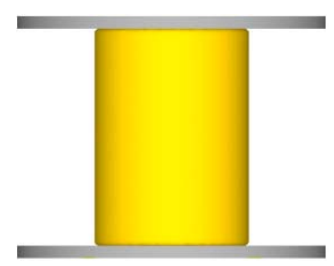

Figure 3. The finite element model of a $\Phi 1 \mathrm{~m} \times 1.4 \mathrm{~m}$ billet.

The parameters of this simulation are as follows: billet material is AISI316L; initial deformation temperature is $1200^{\circ} \mathrm{C}$; pressing speed is $10 \mathrm{~mm} / \mathrm{s}$; during the actual piercing process, there is friction and contact among each other between the anvil and the blank producing a heat transfer process. Therefore the friction coefficient is 0.7 , and the heat transfer coefficient between anvil and billet is 11000 $\mathrm{W} /\left(\mathrm{m}^{2} \mathrm{~K}\right)$; In addition to its own contact heat transfer, the ingot billet and the anvil also contact the air to produce contact heat transfer and radiation heat transfer behavior. In this model, the heat transfer coefficient between billet and air is

$20 \mathrm{~W} /\left(\mathrm{m}^{2} \mathrm{~K}\right)$; and thermal emissivity is 0.7 .

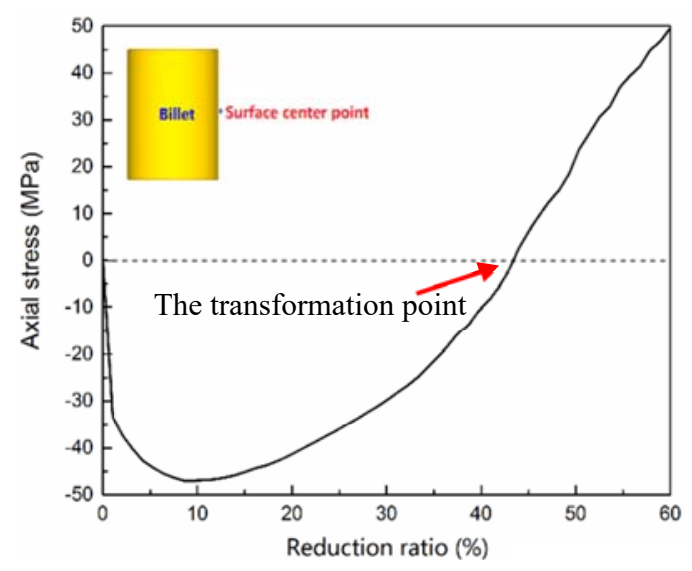

Figure 4. Axial stress change of the billet surface center point during upsetting.

During the upsetting process, axial stress change of the center point on the billet surface is shown in Fig. 4. At the beginning, the surface axial stress is compressive and the stress increases rapidly. As the anvil presses and reduction ratio increases, the axial compressive stress of the billet surface center decreases gradually. When the reduction ratio is $43.4 \%$, the axial compressive stress becomes 0 , and the compressive stress of billet surface center transforms to tensile stress at larger reduction ratio (the compressive stress is negative, and the tensile stress is positive). This point is called transformation point of surface axial stress. The axial stress distribution of billet section at the reduction ratio of $43.4 \%$ and $60 \%$ are showed in Fig. 5 when the reduction ratio is $43.4 \%$, the surface axial stress of the billet surface center is close to 0 . When the reduction ratio is $60 \%$, the surface axial stress has already transformed to tensile stress.

The surface stress changes from compressive to tensile would firstly occur at the center of the billet surface, and the rest part of the surface would also change to tensile with the increase of reduction ratio. Near the surface of the billet, a tensile stress area will be formed, which is easy for minor cracks to propagate. 


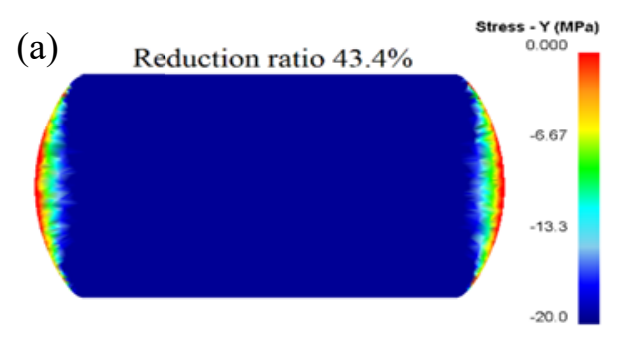

Figure 5 Axial stress distribution of the billet section

The circumferential stress changing process of the billet surface center point is shown in Fig. 6. The circumferential stress is tensile from the beginning and its value increases as the reduction ratio increases. Circumferential stress can only cause longitudinal crack. As Fig. 1 shows, if the initial crack is transverse caused by anvil overlapping during stretching, circumferential tensile stress will not cause its propagation.

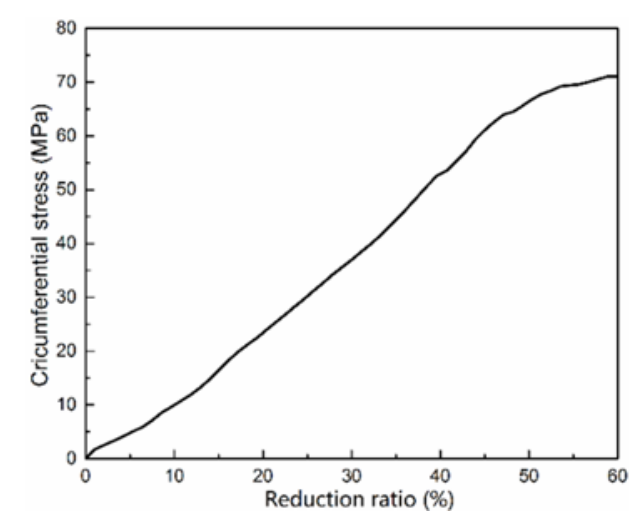

Figure 6. circumferential stress change of the billet surface center point during upsetting process.

\section{Factors affecting transformation point of the surface axial stress during upsetting process}

According to the research above, the transformation point of the surface axial stress from compressive to tensile is an important factor affecting whether the minor cracks will propagate during the upsetting process. Therefore, factors affecting the transformation point are studied. The effect of temperature, height-diameter ratio of billet, pressing speed, friction coefficient between anvil and billet and different materials on the transformation point of surface axial stress are investigated based on the previously established model.

In order to describe the transformation point, critical

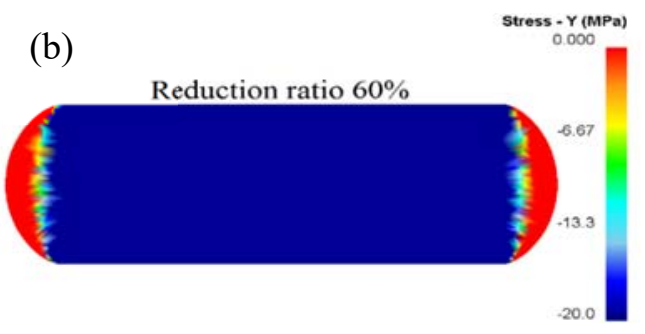

(a) Reduction ratio $43.4 \%$ (b) Reduction ratio $60 \%$.

reduction ratio $\delta c$ is defined as follows: During the upsetting process, when the billet surface center axial stress is 0 , the reduction ratio is called critical reduction ratio, $\delta c$ is presented in Equation (1):

$$
\delta c=\frac{\Delta H c}{H}
$$

where $H$ is the initial height of billet; $\Delta H c$ is the reduction of billet when surface center axial stress is 0 , which also means it is the transformation point from compressive to tensile during the upsetting process.

For a certain upsetting process, only one critical reduction ratio can be obtained. The bigger $\delta c$, the later transformation of surface axial stress from compressive to tensile is, and the smaller is the tensile stress at the same reduction ratio. Fig. 7 is the critical reduction ratio at different deformation conditions during upsetting process. The height-diameter ratio of billet, pressing speed, and friction coefficient between anvil and billet has prominent effect on the surface axial stress transformation, and a very little effect on billet materials and deformation temperature.

During the upsetting process, billet will bulge and become drum shape, which is mainly due to friction between the billet and the anvil. Friction generates great frictional force on the surface of the billet, which prevents the billet expanding uniformly. The billet drum shape will be changed when the friction coefficient is changed. The maximum diameter of the billet varies greatly at the same reduction ratio after upsetting under different friction coefficient [20]. Bulging of the billet is controlled not only by friction, but also by other factors. For billets with large heightdiameter ratio, the effect of friction is weakened, so bulging is less serious. The pressing speed also has effect on bulging when heat transfer between billet and anvils is considered. As Fig.8a) shows, if billet is pressed slowly, the area contacting cold dies have enough time to be cooled, and becomes a "cold 
shell". This cold area can not be deformed during upsetting. So contacting area does not expand in this situation, and bulging of the billet is controlled by the "cold shell". As Fig. 8b) shows, if billet is pressed
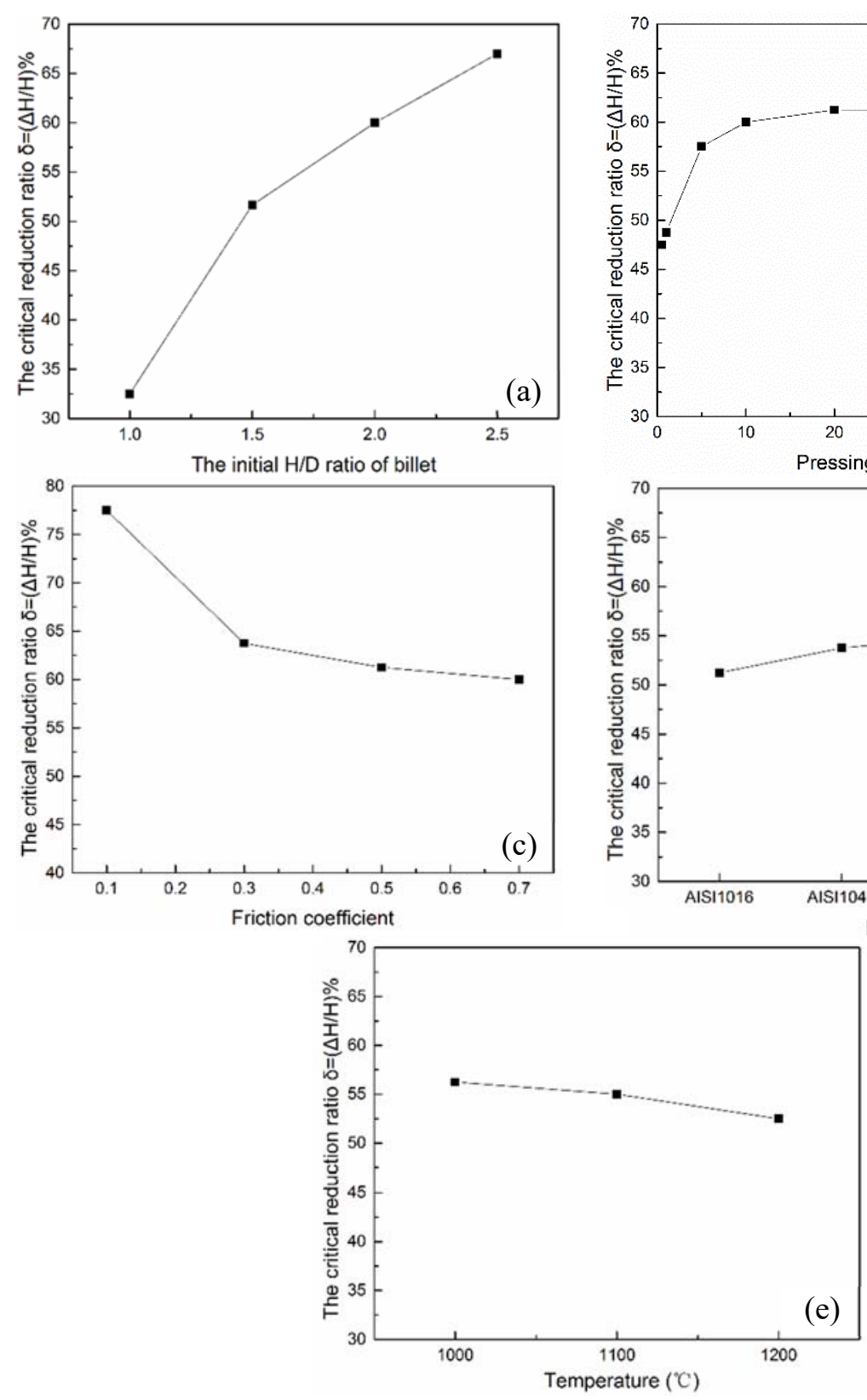

Figure 7. The factors affecting critical reduction ratio during upsetting process. (a)height-diameter ratio of billet (b) pressing speed (c) friction coefficient between anvil and billet (d) material of billet (e) deformation temperature.

Based on the simulations above, it is found that the billet drum shape has an obvious relationship with the surface axial stress. If bulging of the billet is more serious, the surface axial tensile stress will also become larger. Therefore, the surface stress is controlled by bulging in essence. So bulging fast, no "cold shell" will be formed, and bulging of the billet is controlled by friction. So when the billet is pressed faster than a certain speed, the drum shape will not be controlled by the pressing speed.
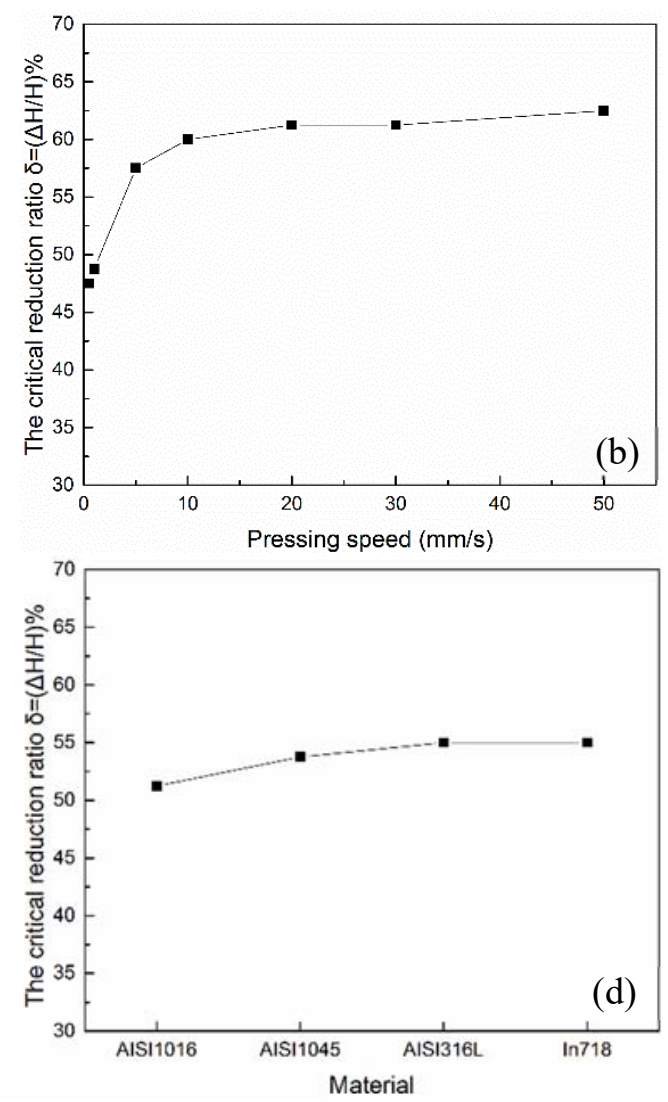

(e) parameter $\mathrm{d} / \mathrm{h}$ was defined to characterize the degree of billet bulging. As Fig. 9 shows, $h$ is the height of billet after upsetting and $\mathrm{d}$ is the horizontal distance between $m$ and $n$ point on the cross section of cylindrical billet after upsetting. So the larger $d / h$ is, the more serious billet bulging is. 

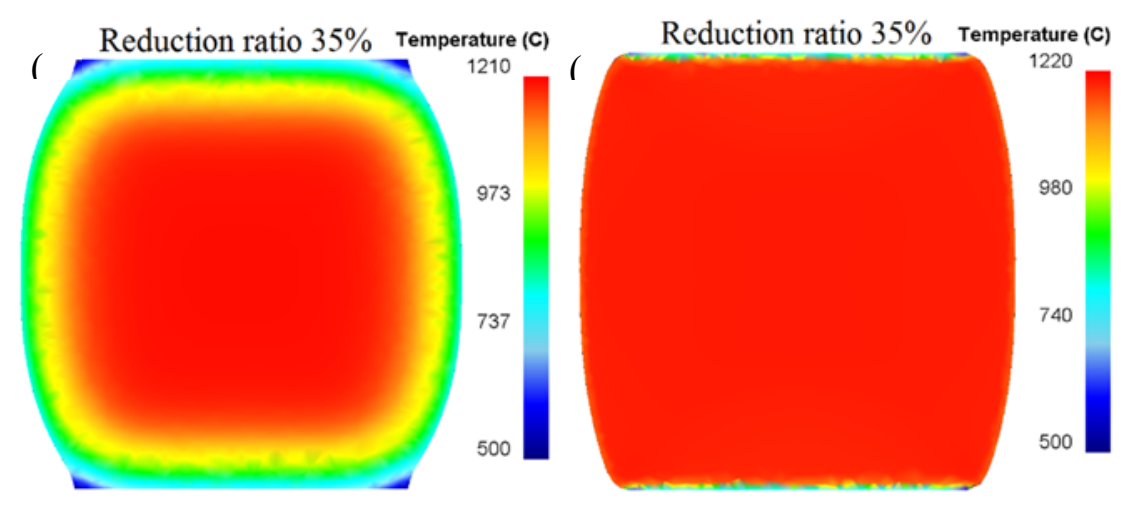

Figure 8. The temperature of billet; (a) Pressing speed $0.5 \mathrm{~mm} / \mathrm{s}$ (b) Pressing speed $50 \mathrm{~mm} / \mathrm{s}$

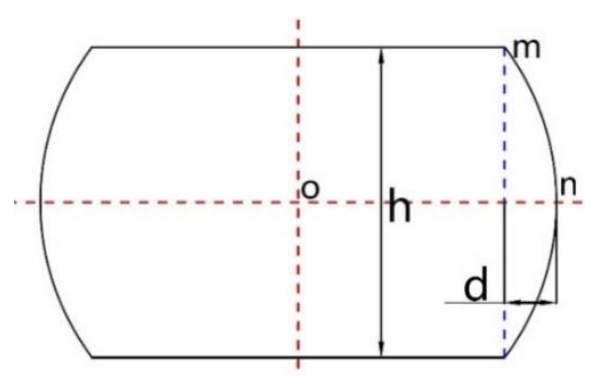

Figure 9. $d / h$ is defined to characterize the degree of billet bulging.

The critical bulging parameter $(\lambda c$ is presented in Equation (2)) can be defined to characterize the bulging status when the billet surface center axial stress reaches transformation point.

$$
\lambda c=\frac{d c}{h c}
$$

where $d_{\mathrm{c}}$ is the horizontal distance between $m$ and $n$ point on the cross section of cylindrical billet when billet surface center axial stress transforms from compressive to tensile; $h_{\mathrm{c}}$ is the height of the billet under this situation.

As Fig. 10 shows, it can be found that critical bulging parameter has little relationship with the factors. The surface axial stress transform from compress to tensile when the value of $d / h$ varies between 0.163 and 0.178 under different deformation conditions. This is a narrow range, and it shows that the surface axial stress transformation point is mainly controlled by bulging. Therefore, the billet bulging parameter during the upsetting process can be used to characterize the values of surface axial stress effectively, and $d / h=0.17$ can be regarded as the critical point of billet surface axial stress transformation from compressive to tensile in the heavy forging upsetting process.

\section{Design of slim waist forging process}

According to the analysis above, minor surface transverse defects formed during stretching may quickly propagate under surface axial tensile stress during following upsetting process. Therefore, slim waist forging process was designed to prevent the transverse crack from propagation. The basic idea of the slim waist forging process is to reduce the diameter of billet center and avoid bulging during upsetting process. During stretching process, the billet can be forged to a slim waist shape. Therefore, during the following upsetting process, bulging will be reduced, the transformation point of the surface axial stress will be delayed or eliminated, and propagation of surface transverse cracks will be restrained.

Slim waist shape billet can be quantitative designed using finite element modeling analysis. Designing the slim waist shape of the billet can avoid bulging and surface axial tensile stress under a certain reduction ratio. The designing process is shown in Fig. 11. The main procedures are as follows: Step 1, the upsetting process of a cylinder billet is calculated, and the billet bulging is removed when the reduction reaches the expected reduction ratio; Step 2, feature points are defined along the center of the section, and reverse calculation is performed by finite element software, so the initial location of the feature points can be obtained. Step 3, the initial location of the feature points are used to design a slim waist shape billet; Step 4, upsetting of designed slim waist shape billet is calculated by finite element modeling and the bulging of slim waist shape billet is verified at the expected reduction ratio; Step 5, the dimensions of slim waist shape billet is modified to get the final shape 


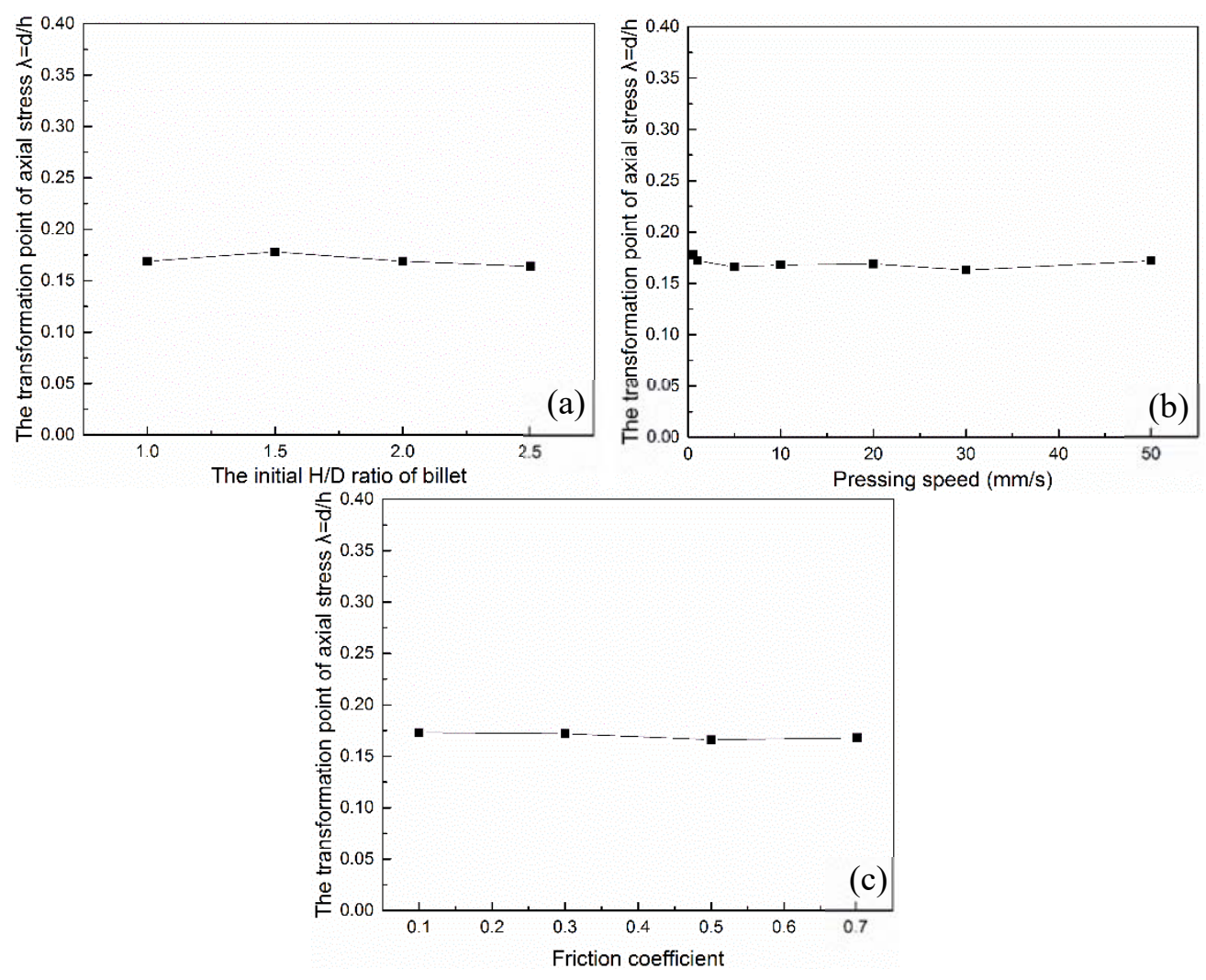

Figure 10. The factors affecting critical bulging parameter during upsetting process. (a) Height-diameter ratio of billet (b) Pressing speed (c) Friction coefficient between anvil and billet.

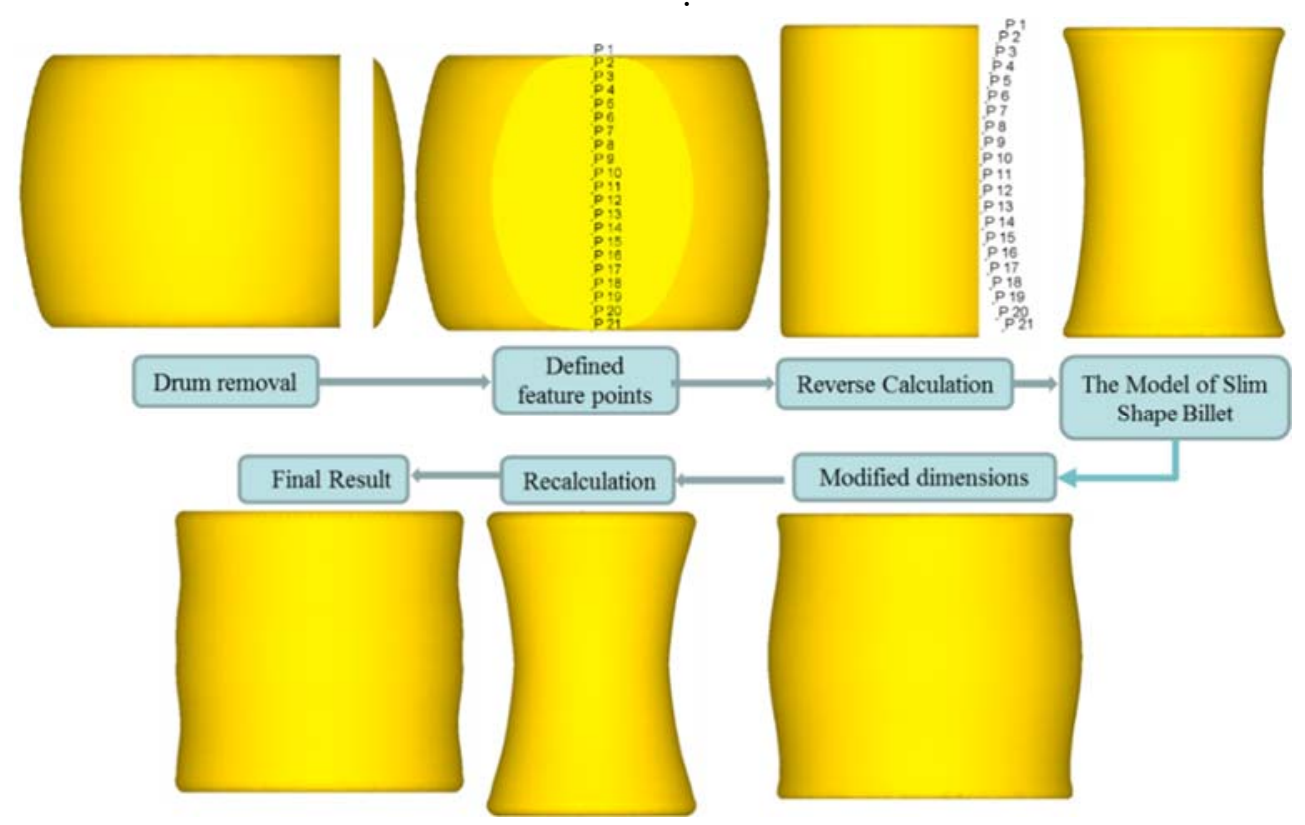

Figure 11. The designing process of slim waist shape billet.

Using this designing method, billet upset to the expected reduction ratio without bulging can be obtained.

The upsetting model of slim waist shape billet was established. The height of the billet is $1.4 \mathrm{~m}$, the maximum diameter is $1 \mathrm{~m}$ and the minimum diameter is $0.7 \mathrm{~m}$. The axial stress change of slim waist shape billet surface center during upsetting process is 
shown in Fig. 12(a). The axial stress is compressive throughout the upsetting process of reduction ratio from 0 to $60 \%$. The surface circumferential stress change of slim waist shape billet surface center is

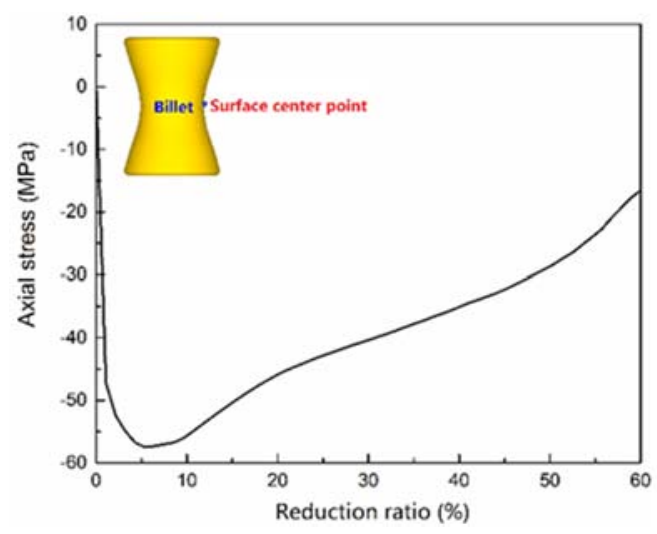

a) shown in Fig. 12(b), It is basically the same as that of the cylindrical billet, so this forging process can only prevent transverse crack, not longitudinal crack.

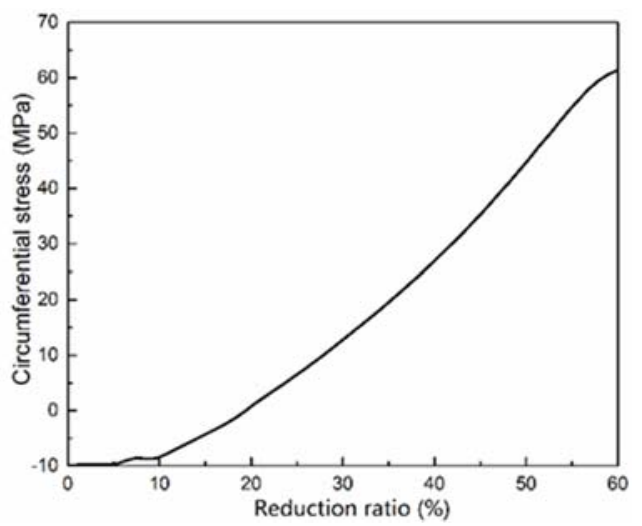

b)

Figure 12 The stress of slim waist shape billet surface center. (a) axial stress (b) circumferential stress.

Fig. 13 is the axial stress distribution on the section of slim waist shape billet at reduction ratio $43.4 \%$.

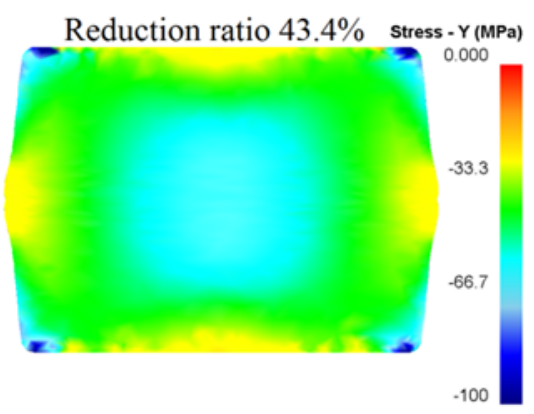

Figure 13 The distribution of axial stress on the section of slim waist shape billet.

The surface axial stress of slim waist shape billet is all compressive. The compressive stress is smallest in the middle of the billet surface, and the stress value is far less than zero. So the transformation point of axial stress from compressive to tensile was eliminated by designing of slim waist shape billet. Fig. 14 is the strain distribution of slim waist shape billet and cylindrical billet at the same reduction ratio. As shown in the figure, strain near side surface of cylindrical billet is smaller during the upsetting process, which means recrystallization is inadequate, and the mechanical property might be impacted. However, the strain is larger in the middle of the slim waist shape billet during the upsetting process. The deformation of slim waist shape billet is more uniformed than the cylindrical billet when the reduction ratio is the same. The hard deformation zone and large deformation zone in billet center are eliminated. The grain size will be refined in the upsetting process of the slim waist shape billet, and the surface cracks will be restrained. It can significantly improve the quality of the heavy forgings.
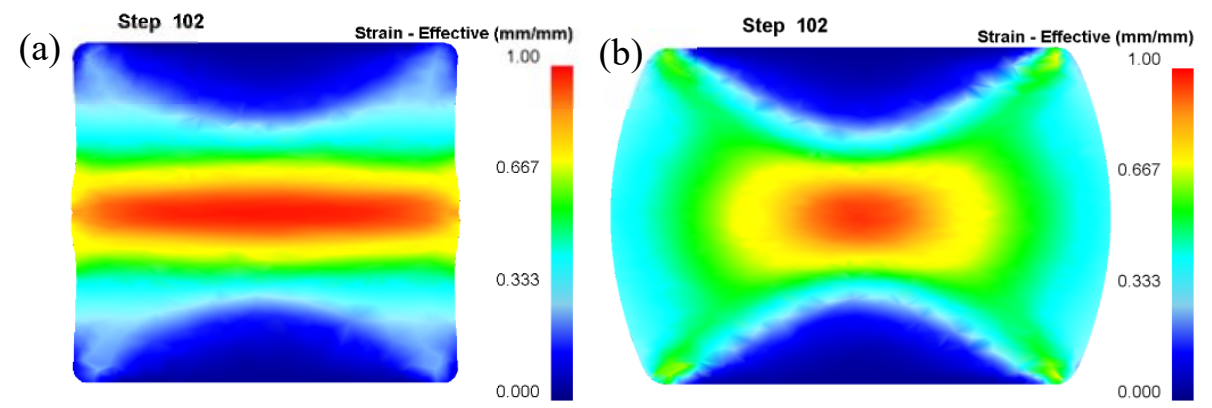

Figure 14 The distribution of strain on the section of billet (a) slim waist shape billet (b) cylindrical billet 


\section{Conclusion}

1. Surface transverse cracks formed during stretching are crack source and may rapidly propagate under surface axial tensile stress during the upsetting process. The axial stress on the surface of cylindrical billet will transform from compressive to tensile during the upsetting process. The axial tensile stress first appears on the side surface center of the cylindrical billet, and the axial stress at near surface of the cylindrical billet will also transform to tensile stress as upsetting continues.

2. Height-diameter ratio of billet, pressing speed, and friction coefficient between anvil and billet has prominent effect on the surface axial stress transformation. But these factors are indirect factors. The surface axial stress is controlled by bulging of the billet in essence.

3. The billet bulging degree during the upsetting process can be used to characterize surface axial stress effectively. Based on the simulations, $\mathrm{d} / \mathrm{h}=0.17$ can be regarded as the critical point of billet surface axial stress transformation from compressive to tensile during upsetting process.

4. The slim waist forging process is proposed. The transformation of surface axial stress from compressive to tensile during the upsetting process can be delayed or eliminated by designing of slim waist shape billet. Comparing with cylindrical billet, its strain distribution is more uniformed

\section{References}

[1] Rauch, L., Chmura, A., Gronostajski, Z., Polak, S., Pietrzyk, M.: Cellular automata model for prediction of crack initiation and propagation in hot forging tools, Archives of Civil and Mechanical Engineering, 3 (2016), 16, 437-47.

[2] Shen, K., Xu, L., Guo, Y., Shi, J., Wang, M.: Effect of microstructure on hydrogen diffusion and notch tensile strength of large steel forging, Materials Science and Engineering, (2015), 628, 149-53.

[3] Guo, W. M., Xu, N., Ding, N., Shi, J. B., Wu, C. M. L.: An analysis of crack evolution of a 12Cr13 stainless steel during forging process, Case Studies in Engineering Failure Analysis, (2015), 4, 94-9.

[4] Wang, M., Li. D., Wang, F., Zang, X., Li, X., Xiao, H., et al.: Analysis of laminated crack defect in the upsetting process of heavy disk- shaped forgings, Engineering Failure Analysis, 3 (2016), 59, 197-210.

[5] Zatočilová, A., Palošek, D., Brandejs, J.: Imagebased measurement of the dimensions and of the axis straightness of hot forgings, Measurement, (2016), 94, 254-64.

[6] Zhang, Y., Yang, Y., Li, Q., Y, Li.: Study on heat transfer model of coolant boundary layer during high speed cutting process, International Journal of Heat \& Mass Transfer, (2017), 114,1304-1313.

[7] Gao, Z., Niu, J.: Research on cold crack sensitivity of high-strength wear-resistant steel NM360 after welding, Engineering Review, 1 (2015), 35, 61-66.

[8] Vukelic, G., Brnic, J.: Numerical Prediction of Fracture Behavior for Austenitic and Martensitic Stainless Steels, International Journal of Applied Mechanics, 4 (2017), 09.

[9] Zhang, L., Ye, B., Liao, W., Zhou, H., Guo, W., Wang, Q., et al.: Microstructure evolution and mechanical properties of AZ91D magnesium alloy processed by repetitive upsetting, Materials Science and Engineering A, (2015), 641, 62-70.

[10] Sun, M. Y., Li, D. Z., Li, Y. Y., Ling, J., Shen, C. P.: Simulation and experiment study of bending process of large marine crankthrow, Acta Metallurgica Sinica, (2005),1261-6.

[11] Arikawa, T., Yamabe, D., Kakimoto, H.: Influence of Anvil Shape of Surface Crack Generation in Large Hot Forging Process, Procedia Engineering, (2014), 81, 480-5.

[12] He, J., Liu, J., Cui, Z., Yang, C., Chen, F.: Ductile Fracture Prediction of 316LN Stainless Steel in Hot Deformation Process, Journal of Iron and Steel Research, International, (2014), 21, 923-30.

[13] Khatak, H.S.: Applications of Fracture Mechanics in Stress Corrosion Cracking and Introduction to Life Prediction Approaches, Corrosion of Austenitic Stainless Steels: Woodhead Publishing, (2002), 190-217.

[14] Zhang, X., Zeng, W., Shu, Y., Zhou, Y., Zhao, Y., Wu, H., et al.: Fracture criterion for predicting surface cracking of Ti40 alloy in hot forming processes, Transactions of Nonferrous Metals Society of China, (2009), 19, 267-71.

[15] Beremin, F.M.: Cavity formation from inclusions in ductile fracture of A508 steel, Metallurgical Transactions A, 5(1981) 
[16] Thomson, R. D., Hancock, J.W.: Ductile failure by void nucleation, growth and coalescence, International Journal of Fracture, 2 (1984)

[17] Liu, Z. B., Nie, S. M., Wang, L. D.: A New Theory for Upsetting a Cylinder between Flat Platens, Chinese Journal of Mechanical Engineering, 4 (1992), 5, 297-303.

[18] Qiong, L. I.: Principle of mechanics for removal of crack in ingot throuth upset by conical plates, Journal of Changsha Communications University, (1999), 15.
[19] Zuo, X., Wei, Y., Chen, J., Zeng, L., Ruan, X.: $3 D$ FEM simulation of multi-stage forging process using solid modeling of forging tools, Journal of Materials Processing Technology, (1999), 91, 191-5.

[20] Zhang, X. X.: Research on void evolution in large ingot during hot forging [Dissertation], Shanghai Jiao Tong University, (2009) 